\title{
FORMAÇÃO CONTINUADA E POLÍTICAS EDUCACIONAIS: RELAÇÃO DE UM GRUPO DE PEDAGOGAS COM A PROGRESSÃO CONTINUADA
}

\author{
Anoel Fernandes \\ Pontifícia Universidade Católica de São \\ Paulo
}

\begin{abstract}
Resumo: $O$ presente estudo tem por objetivo verificar se a formação continuada realizada por um grupo de professoras atuantes no ciclo I da rede pública estadual paulista interfere nas percepções que possuem sobre a política educacional que, no ano de 1998, organizou o ensino em ciclos com progressão continuada. $\mathrm{O}$ referencial teórico para análise dos dados é à teoria critica da sociedade. Busca-se responder a seguinte questão: a formação continuada interfere nas percepções de professoras atuantes no ciclo I da rede pública estadual paulista sobre a organização do ensino em ciclos com progressão continuada? Como procedimento de pesquisa, aplicou-se um questionário para 37 professoras. Os dados apontaram que a formação continuada das professoras é realizada, em sua maior parte, pelo próprio lócus de trabalho em que estão inseridas. Tais dados, ao serem cotejados com o referencial adotado, sublinham que a formação no âmbito do trabalho é pseudoformação por ser uma formação voltada para atender às demandas do sistema.
\end{abstract}

Palavras chave: política educacional; formação de professores; progressão continuada. 


\title{
ONGOING FORMATION AND EDUCATIONAL POLICIES: A GROUP OF PEDAGIGISTS' RELATIONSHIP WITH CONTINUED LEARNING PROGRESSION
}

\begin{abstract}
This study aims to check as to whether ongoing formation performed by a group of teachers working in public, São Paulo State schools' Cycle I interferes in the perceptions they have about educational policy, which organized - in the year of 1998 - teaching into cycles with continued learning progression. The theoretical reference for analyzing data was the critical theory of society. Attempt was made as to answer the question that follows: how does continued learning progression interfere in the work of teachers who are active in Cycle I of the public São Paulo state's schools about the organization of teaching into cycles with continued learning progression? As a research procedure a questionnaire was applied to 37 teachers. The data showed that the teachers' ongoing formation is mostly carried through by the workplace itself, where they are inserted. When such data were plotted with the adopted reference, they point out that the formation in the work sphere means pseudo-formation, for it aims at meeting the system's demands.
\end{abstract}

Keywords: educational policy; teachers' formation; continued learning progression. 
Anoel Fernandes

\section{Introdução}

O presente texto visa apresentar algumas considerações sobre a formação continuada de professores. Devido à amplitude de fatores que constituem a temática, buscou-se apreender as experiências de formação continuada de um grupo de 37 professoras atuantes no ciclo I do ensino fundamental da rede pública estadual paulista mediante a forma que manifestam lidar com as políticas educacionais, nesse caso específico, a organização do ensino em ciclos com progressão continuada.

Para tanto, apresenta-se inicialmente algumas considerações sobre a reforma educacional realizada na rede pública estadual paulista no ano de 1998, que reorganizou o ensino, retirando o modelo seriado até então em vigência, para a inserção do regime de ciclos com progressão continuada. Posteriormente discorre-se sobre a formação de professores, com considerações a partir da teoria crítica da sociedade, para, em seguida analisar as experiências de formação continuada das professoras, na qual o intuito é verificar as percepções que estabelecem com a organização do ensino.

Como ponto de partida, destaca-se inicialmente o fato de que no ano de 1998 houve uma reformulação da educação na rede pública estadual paulista. Dentre as mudanças a que mais causou impacto foi à organização do ensino em ciclos mediante o regime de progressão continuada. Dias-da-Silva e Lourencetti (2002) enfatizam que a implantação da organização do ensino em ciclos com progressão continuada foi "certamente o período de maior efervescência nas escolas públicas paulistas nos últimos anos" (DIAS-DA-SILVA e LOURENCET, 2002, p.23), ou seja, a reforma que mais impactou na "vida" escolar. 
Fator de grandes discussões políticas ${ }^{1}$ e acadêmicas a progressão continuada deixa evidente algumas razões dispostas oficialmente, mais precisamente, entre outros aspectos a redução dos índices de repetência e evasão. Isso fica patente, quando no ano de 1997, o Conselho Estadual de Educação aprovou a Indicação n. ${ }^{\circ}$ 08/97 e a Deliberação $n^{0}$ 09/97 que implantaram o regime de progressão continuada, na rede pública estadual paulista a partir do ano de 1998, na qual as reprovações dos alunos deveriam ocorrer primordialmente nos anos finais dos ciclos $-4^{\mathrm{a}}$ e $8^{\mathrm{a}}$ séries e atualmente $1^{\mathrm{o}}$ ao $5^{\mathrm{o}}$ ano.

Alguns pesquisadores da progressão continuada têm feito diversas críticas sobre a que veio atender a progressão continuada no estado de São Paulo. Estudioso dessa temática, Freitas (2003, p.9) ao posicionar-se sobre a progressão continuada e suas finalidades afirma que "a progressão continuada tem como perspectiva central a correção de fluxo". Dias (2004) ao posicionar-se sobre de onde a progressão continuada partiu, destaca que "a progressão continuada, camuflada de organização escolar em ciclos, implica na priorização não do aprendizado, mas com a promoção automática na diminuição das taxas de repetência e evasão, não no aumento dos investimentos, mas com a racionalização destes" (p.63),

Ao discutir a temática da diferença tanto no surgimento quanto nas funções que vieram atender os ciclos e a progressão continuada, Freitas (2004) afirma que a última já estava na agenda dos liberais desde que estes se apropriaram do lema Educação para Todos no início da década de 1990. Já os ciclos foram inseridos no debate a partir de uma perspectiva crítico-social. $\mathrm{O}$ autor afirma, ainda, que o surgimento

\footnotetext{
1 Embora este não seja o foco desta pesquisa, um fator a ser ressaltado é que última disputa eleitoral para o governo do estado de São Paulo (2010), os dois principais concorrentes se manifestaram sobre a questão da progressão continuada, sendo que um deles a defendia, enquanto o outro tinha como uma de suas metas acabar com a progressão continuada no estado de São Paulo.
}

Olh@res, Guarulhos, v. 2, n. 2, p. 86-110. Dezembro, 2014. 
da progressão continuada “(...) teve como objetivo meramente lidar com os problemas educacionais dentro de uma perspectiva economicista: liberando fluxos e enxugando custos" (FREITAS, 2004, p.6), enquanto os ciclos:

(...) propõem alterar os tempos e os espaços da escola de maneira mais global, procurando ter uma visão crítica das finalidades educacionais da escola. Está em jogo mais do que simplesmente liberar fluxos, ou sair-se bem em avaliações do sistema, ou, ainda tirar a avaliação formal juntando séries em planejamentos plurianuais (FREITAS, 2004, p. 11).

Reforça, ainda, Freitas (2002) que o regime de progressão continuada tem a finalidade de reduzir os custos econômicos, sociais e políticos das formas de exclusão objetivas - repetência e evasão -, sem alterar a seletividade da escola, criando um "campo de exclusão subjetiva" (FREITAS, 2002, p.301). Já os ciclos devem ser mecanismos de resistência à lógica seriada, mas precisam ser vistos como oportunidades para se elevar a conscientização dos professores, alunos e pais, revelando a estes as reais travas para o desenvolvimento da escola e da sociedade, "e não apenas serem vistos como uma solução técnico-pedagógica para a repetência" (FREITAS, 2002, p.321). Dadas algumas diferenças dos conceitos de ciclos e progressão continuada, o autor, ao se manifestar sobre a associação dos ciclos com a progressão continuada, denuncia que no estado de São Paulo o caso é mais grave, em comparação com outros estados (FREITAS, 2004), já que com a implantação da progressão continuada coloca em risco a ideia de ciclo, pois reforça a confusão acerca do tema de pais, alunos e professores.

E é justamente devido às especulações e críticas em torno da organização do ensino em ciclos com progressão continuada que o presente texto visa apreender a formação continuada das professoras, focalizando se e como tal formação relaciona-se com a forma de Olh@res, Guarulhos, v. 2, n. 2, p. 86-110. Dezembro, 2014. 
lidarem com a referida política educacional. Busca-se tencionar como a mudança que mais alterou o cotidiano das escolas públicas estaduais paulista nos últimos tempos relaciona-se com as experiências de formação continuada das professoras. Para a circunscrição de tal tarefa, adota-se como referencial teórico a perspectiva de formação tal como desenvolvida pela teoria crítica da sociedade, conforme apresentado a seguir.

A formação de professores: considerações a partir da teoria crítica da sociedade

Como ponto de referencia para estabelecer a posição da teoria crítica da sociedade sobre a formação, apresenta-se a definição de Adorno (1972). Ao discorrer sobre o conceito de formação ao autor define-a da seguinte maneira: "la formación no es outra cosa que la cultura por el lado de sua propriación subjetiva" (ADORNO, 1972, p. 142-43). No entanto, Resende (2003) aponta que a cultura não é independente, quer da sociedade, quer da natureza, quer do indivíduo categorias privilegiadas na teoria crítica. Conforme a autora "os nexos estabelecidos entre os conceitos de sociedade, indivíduo, cultura e natureza estão sempre presentes, independentemente de qualquer aspecto que esteja sendo analisado, portanto, seria difícil refletir acerca dessa teoria sem analisar a questão da formação" (RESENDE, 2003, p. 38), pois, como enfatiza Adorno (1972), o problema da formação é mais abrangente do que possa parecer à primeira vista. Conforme o autor:

Lo que hoy está patente como crisis de la formación cultural ni es mero objeto de la disciplina pedagógica, que tendría que ocuparse directamente de ello, ni puede superarse con uma sociología de yuxtaposiciones - precisamente de la formación misma. Los síntomas de colapso de la formación cultural que se advierten por todas partes, aunenel estrato de las personas cultas, no se agotan com la sinsuficiencias del sistema educativo y de los métodos de educación criticadas desde hace generaciones; las reformas pedagógicas aisladas, por

Olh@res, Guarulhos, v. 2, n. 2, p. 86-110. Dezembro, 2014. 
indispensables que sean, no nos valen, y al aflojar las reclamaciones espirituales dirigidas a los que han de ser educados, así como por una cándidad es preocupación frente al poderío de la realidade extrapedagógica sobre éstos, podrían más bienen ocasiones, reforzar la crisis (ADORNO, 1972, p. 141-42).

Para a teoria crítica, a cultura não é independente da sociedade, da natureza e do indivíduo. Os nexos estabelecidos entre os conceitos de sociedade, indivíduo, cultura e natureza estão sempre presentes, independentemente de qualquer aspecto que esteja sendo analisado (RESENDE, 2003). Portanto, seria difícil refletir acerca dessa teoria sem analisar a questão da formação. Diante disso, vem à tona o fato de que para analisar a formação na sociedade contemporânea é necessário apreender a dialética imanente ao próprio processo de reprodução material da sociedade, considerando a forma social em que a formação se encontra.

Tal reflexão torna-se pertinente, pois, como se pode depreender, o colapso da formação é resultante de um processo social amplo, cujas determinações devem ser apreendidas também fora do âmbito estritamente cultural e pedagógico. Dessa forma, para conhecer o processo de formação, no âmbito de reprodução da vida real dos homens, é necessário investigá-la no conjunto da sociedade em que ela se manifesta, ou seja, é preciso considerá-las "no plano da própria produção social da sociedade em sua forma determinada" (MAAR, 2003, p.471).

Horkheimer e Adorno (1973) mencionam que o indivíduo se forma com os outros e com o meio, isto é, na convivência. Os autores são enfáticos no posicionamento sobre o processo formativo, afirmando que este deve estimular o pensamento próprio e a consciência, fatores fundamentais para o desenvolvimento da crítica e, portanto, das possibilidades de agir com autonomia ante as imposições da sociedade. Olh@res, Guarulhos, v. 2, n. 2, p. 86-110. Dezembro, 2014. 
Entretanto, Crochík (2000, p. 163) afirma que a sociedade burguesa privou a formação de sua base, surgindo a pseudoformação, que é "a integração e domesticação do indivíduo (...) a pseudoformação impede o pensamento". Diante dessa situação, os indivíduos não se apropriam livremente da cultura, prevalecendo o momento da adaptação aos padrões de conduta, de comportamento e de pensamento e a dificuldade de resistir às pressões sociais.

E é justamente pelas determinações sociais dos sujeitos que recai o interesse de investigação aqui tencionado, a saber: a formação continuada interfere nas percepções de professoras atuantes no ciclo I da rede pública estadual paulista sobre a organização do ensino em ciclos com progressão continuada?

Adorno (2006), no texto A filosofia e os professores, escrito a mais de meio século, ao direcionar suas reflexões a respeito da prova geral de filosofia dos concursos para a docência em ciências nas escolas superiores do estado de Hessen, na Alemanha, destaca que

A colcha de retalhos formada de declamação ideológica e de fatos que foram apropriados, isto é, na maior parte das vezes decorados, revela que foi rompido o nexo entre objeto e reflexão. A constatação disso nos exames é recorrente, levando imediatamente a concluir pela ausência da formação cultural (Bildung) necessária a quem pretende ser um formador (ADORNO, 2006, p.63).

Ao apontar as causas dessa ausência de formação, Adorno (2006, p.71) assinala que "as condições sociais como a origem, em relação à qual todos são impotentes, são culpadas pela insuficiência do conceito enfático de formação: a maioria não teve acesso aquelas experiências prévias a toda educação explícita de que a formaçãocultural se nutre". Ao direcionar suas reflexões sobre a formação diante do sistema capitalista, Adorno (1972) enfatiza que

La ideia misma de formación, que tiene em sí uma esencia antinómica: sus condiciones son la autonomia y la liberdad, no obstante locual remite, a la vez, a estructuras de um orden pretextado frente a cada persona singular, em certo

Olh@res, Guarulhos, v. 2, n. 2, p. 86-110. Dezembro, 2014. 
sentido heterônomo y, por ello, nulo, a cuya imagem unicamente es capaz desta última de formarse. De ahí que em el instante em que hay formación, propriamente no lahaya: em su origen está ya incluída teleológivamentesu ruina (p. 154-55)

Diante de tais discussões parece ser evidente que há um colapso da formação geral, emergindo daí a necessidade de aprofundar a temática da formação docente, pois entende-se que a prática dos professores é o resultado do entrelaçamento daquilo que vivem no trabalho com as experiências de formação cultural e profissional. Nesse sentido, formação adquire um significado mais profundo: deve promover não a cultura com um fim em si mesmo, não a preparação para o trabalho, “(...) mas o próprio esclarecimento com suas contradições, para que essas possam ser superadas, não somente no plano do pensamento, mas no plano da ação" (CROCHÍK, 2003, p. 69). No caso da formação de professores, defende-se a proposta de que esta não deve ser voltada para o exercício estrito da profissão, indo além dos conhecimentos das técnicas e didáticas de ensino.

De qualquer modo, verifica-se a existência de um grupo significativo de investigações sobre os saberes mobilizados por professores durante suas práticas. Tais pesquisas apontam que uma das maneiras do professor formar-se para a docência é durante o próprio exercício do magistério; assim, além de receber formação acadêmica, o professor forma-se também no trabalho. Não se trata de desconsiderar esses resultados e nem a aquisição de conhecimentos advindos diretamente da prática pedagógica, mas inquirir sobre as condições em que esses conhecimentos são produzidos: aquilo que o professor elabora com base na sua experiência é resultado de um processo de formação ou é apenas testemunho da alienação?

A propósito desse debate, Horkheimer e Adorno (1985) indicam que essa imersão na prática responde a necessidade de Olh@res, Guarulhos, v. 2, n. 2, p. 86-110. Dezembro, 2014. 
adaptação dos indivíduos ao estabelecido. Conforme os autores, “socialização radical significa alienação radical” (HORKHEIMER E ADORNO, 1985, p.66). Essas ponderações remetem para a indagação sobre os cursos de formação continuada que são oferecidos pelos órgãos gestores (na própria escola ou em outro local) e sobre o potencial da prática cotidiana na formação docente. Essas situações podem levar à socialização radical e, em consequência, perpetuar a alienação do professor. Portanto, temos que questionar o valor do trabalho, e é o que faz Crochík (2003, p. 69) quando afirma que "o trabalho, como constituinte do homem, por ser alheio ao consumo do produto do trabalhador, não o forma, antes o deforma, pois no momento que produz, é expropriado". Evidentemente, é necessário examinar se o que se aplica ao trabalho em geral também pode servir de parâmetro para a análise do magistério em particular.

Tendo em vista as discussões sobre a formação dos professores no próprio trabalho, vale retomar a pergunta de Marcuse (1967, p. 56): “quem educa os educadores e onde está a prova de que eles estejam na posse do "bem"?". O autor clama pela validade de sua pergunta justificando-a que em "certas formas democráticas de governo nas quais as decisões finais sobre o que é bom para a nação são dadas por representantes eleitos (ou melhor, endossadas por representantes eleitos)". Cabe refletir se a formação docente no próprio ambiente de trabalho não seria uma simples forma de sedimentar as prescrições oficiais, visto que esse processo está centrado, muitas vezes, na divulgação de políticas educacionais, ou seja, o acesso à formação é mediado pelos representantes do governo, nesse caso, os elaboradores das propostas educacionais. Entre as consequências dessa situação, pode-se supor que se trata apenas da inculcação das prescrições oficiais.

Olh@res, Guarulhos, v. 2, n. 2, p. 86-110. Dezembro, 2014. 
Dias-da-Silva e Lourencetti (2002, p.24), ao discutirem a relação dos conhecimentos dos professores e as reformas educacionais, enfatizam que "ouvir os docentes, interpretar suas concepções e práticas, talvez possibilite ressignificar sua denunciada resistência à mudança ou sua incompetência em implantar as reformas". Por isso, é importante entender essas professoras submetidas às emanações oficiais. Como afirma Marcuse (1967):

\begin{abstract}
Ao falar sua própria linguagem, as criaturas [as pessoas] falam também a linguagem de seus senhores, de seus benfeitores, de seus anunciantes. Assim, elas não expressam a si mesmas, os seus próprios conhecimentos, sentimentos e aspirações, mas também algo diferente delas. Ao "descreverem por si mesmas" a situação política, seja a de sua cidade natal, seja a do cenário internacional, elas (e o termo "elas" também incluiu a nós os intelectuais que conhecemos a situação e a criticamos) descrevem o que "seu" meio de comunicação em massa lhes diz - e isso se funde com o que elas realmente pensam, veem e sentem (MARCUSE, 1967, p. 182-83, grifos do autor).
\end{abstract}

Assim sendo, as respostas das professoras podem apontar se a formação continuada por elas realizada é uma real formação ou apenas uma socialização como testemunho da imersão conformista ao que lhes são dispostos pelas políticas educacionais, nesse caso, a organização do ensino em ciclos com progressão continuada.

\title{
Método e sujeitos da amostra
}

Como procedimento de pesquisa, optou-se pela elaboração de um questionário e aplicação ${ }^{2}$ em um grupo de professoras do ciclo I. Tal questionário foi composto por questões fechadas e, também, por questões abertas, com as quais se objetivou averiguar as respostas que indivíduos dão a determinado questionamento (SELLTIZ et al., 1974).

\footnotetext{
2 O questionário foi aplicado entre os meses de setembro e novembro do ano de 2012.

Olh@res, Guarulhos, v. 2, n. 2, p. 86-110. Dezembro, 2014.
} 
A pesquisa foi realizada em 10 escolas situadas no município de Campinas-SP e pertencentes à Diretoria de Ensino Região Campinas Oeste (DERCO). Estas possuem 160 professoras exercendo a docência no ciclo I. De antemão, um fator a ser ressaltado diz respeito à dificuldade de acesso às unidades escolares e, por conseguinte, de adesão das professoras. Os Horários de Trabalhos Pedagógicos Coletivos (HTPCs) nas escolas onde estão situados os sujeitos que fizeram parte da amostra ocorrem em dois dias da semana e, em alguns casos, o grupo de professoras é dividido e as reuniões acontecem em dias distintos. Por conta disso - e devido à dispensa das professoras ter sido autorizada pelo dirigente de ensino somente em uma reunião de HTPC -, a apresentação do questionário foi feita a 73 professoras. Desse total, 37 aderiram à pesquisa.

\section{Considerações sobre a formação continuada das professoras}

Como ponto de partida, ressalte-se que a ênfase recai sobre a formação continuada das professoras, entendida esta como possibilidade de formação cultural. Também são considerados os conhecimentos adquiridos no próprio decorrer da docência. Tais aspectos formativos serão tomados a partir dos lugares onde realizaram cursos e de sua natureza, enfim, são informações que podem elucidar as experiências formativas das professoras, uma vez que para analisar a formação e a pseudoformação considera-se ser necessário considerá-las, "no plano da própria produção social da sociedade em sua forma determinada" (MAAR, 2003, p.471). Tendo como referencia tal reflexão, buscou-se inicialmente situar o cruzamento entre os cursos de formação continuada realizados pelas professoras e o tempo de experiência na docência.

Olh@res, Guarulhos, v. 2, n. 2, p. 86-110. Dezembro, 2014. 
Anoel Fernandes

Tabela 1: Relação entre tempo de experiência no magistério (em anos) e realização de cursos de atualização profissional

\begin{tabular}{l|ccccccc}
\hline \multicolumn{1}{c|}{ Tempo de experiência na docência } & $\begin{array}{c}\text { Até } \mathbf{5} \\
\text { anos }\end{array}$ & $\mathbf{6 - 1 0}$ & $\mathbf{1 1 -}$ & $\mathbf{1 6 -}$ & $\mathbf{2 1 -}$ & $\begin{array}{c}+2 \\
\text { To }\end{array}$ & $\begin{array}{c}\text { To } \\
\text { tal }\end{array}$ \\
$\begin{array}{l}\text { Realizou atualização } \\
\text { profissional: }\end{array}$ & & & & & & & \\
& & & & & & & \\
\hline Sim & 5 & 1 & 5 & - & 9 & 5 & $\mathbf{2 5}$ \\
Não & 2 & 6 & - & 3 & 1 & - & $\mathbf{1 2}$ \\
\hline TOTAL & $\mathbf{7}$ & $\mathbf{7}$ & $\mathbf{5}$ & $\mathbf{3}$ & $\mathbf{1 0}$ & $\mathbf{5}$ & $\mathbf{3 7}$ \\
\hline
\end{tabular}

$\mathrm{Na}$ tabela 1 verifica-se que 25 professoras fizeram algum curso de atualização/formação continuada e 12 não realizaram nenhum curso, ou seja, aproximadamente $1 / 3$ das professoras mencionaram nunca ter feito qualquer curso. Já o cruzamento dos dados permite identificar que, das 37 professoras, 32 podem ser consideradas experientes devido ao fato de possuírem mais de cinco anos de exercício docente. E, especificamente, das 12 professoras que afirmaram nunca ter feito qualquer curso de atualização, duas possuem até cinco anos na docência e também são formadas a menos de cinco anos; seis possuem de 6 a 10 anos de docência, três possuem de 16 a 20 anos; e uma de 21 a 25 anos. Dessa forma, 10 das 12 professoras que afirmaram nunca terem feito curso de formação/atualização profissional estão a um tempo significativo no magistério, com destaque para quatro professoras, que estão entre 16 e 25 anos e manifestaram nunca terem feito qualquer curso.

Situado o tempo de atuação tanto das professoras que realizaram cursos, quanto das que mencionaram nunca terem realizado curso algum, realizou-se o cruzamento dos dados referentes ao tipo de curso e as instituições promotoras. Ao responderem sobre os cursos realizados após a formação inicial, as professoras tiveram certa dificuldade em diferenciarem extensão de especialização. O pesquisador sempre que solicitado sugeriu que os cursos acima de 360 Olh@res, Guarulhos, v. 2, n. 2, p. 86-110. Dezembro, 2014. 
horas são caracterizados como especialização, como definido para efeito de evolução funcional na carreira pela Secretaria de Educação do Estado de São Paulo (SEE/SP), ao passo que cursos com carga horária inferior a 360 horas são classificados como extensão. Sendo assim, somente sete professoras realizaram cursos de especialização e nenhuma fez pós-graduação strito sensu, tal como explicitado na tabela a seguir.

Tabela 2: Cursos e instituições promotoras de cursos realizados pelas professoras

\begin{tabular}{l|ccc|c}
\hline \multicolumn{1}{c|}{$\begin{array}{c}\text { Cursos de formação continuada } \\
\text { Instituições em que } \\
\text { realizaram os cursos de } \\
\text { atualização/formação continuada }\end{array}$} & Extensão & Especialização & $\begin{array}{c}\text { Mestrado/ } \\
\text { Doutorado }\end{array}$ & Total \\
\hline $\begin{array}{l}\text { Cursos da SEE/Diretoria de Ensino } \\
\text { Em faculdades/universidades privadas }\end{array}$ & 21 & - & - & $\mathbf{2 1}$ \\
Em universidades públicas & 1 & 5 & - & $\mathbf{6}$ \\
Outros & - & 1 & - & $\mathbf{1}$ \\
\hline TOTAL & $\mathbf{2 2}$ & 1 & - & $\mathbf{1}$ \\
\hline
\end{tabular}

O que chama a atenção na tabela 2 é o fato de que 25 professoras que realizaram alguma formação, além da inicial, concluíram 29 cursos; destes, 21 foram oferecidos pela própria SEE/SP. Tal dado merece atenção especial, pois permite questionar se a formação relacionada básica e estreitamente ao exercício da profissão possibilita algo além da adaptação. Sugere-se que os cursos oferecidos pela $\mathrm{SEE} / \mathrm{SP}$ são predominantemente voltados para a integração do professor à política educacional promovida na rede estadual de ensino ${ }^{3}$.

${ }^{3}$ Para exemplos de como cursos oferecidos pela SEE/SP visam à integração dos professores à política educacional cita-se a dissertação de mestrado - Fernandes (2009) - que, ao verificar o processo de inserção dos professores de Educação Física na rede estadual no ano de 2003, identificou-se que foi oferecido aos professores reuniões periódicas por um período de aproximadamente 2 anos - em caráter de formação continuada - nas Diretorias de Ensino. Tais reuniões tinham como foco inicialmente formar os professores para a implantação da proposta oficial que entrava em vigência, e após a implantação, as reuniões eram tanto para reafirmações da proposta oficial, quanto para apresentação por parte dos professores dos Olh@res, Guarulhos, v. 2, n. 2, p. 86-110. Dezembro, 2014. 
Dito de outra maneira, esses cursos são meios encontrados pelos idealizadores das proposições oficiais para inculcação dos padrões que se pretende disseminar, inclusive lançando mão do conhecimento produzido nas faculdades de educação; ao fazerem isso, tal tipo de formação influencia o pensamento e a atuação dos profissionais que estão na escola. Ao discorrer sobre a relação entre formação e trabalho, Crochík (2003, p. 69) enfatiza que este último, "como constituinte do homem, por ser alheio ao consumo do produto do trabalhador, não o forma, antes o deforma, pois no momento que produz, é expropriado". É evidente que a relação direta entre o trabalhador assalariado em geral e a atividade docente não pode ser feita sem certos cuidados, mas o fato da formação continuada estar imediatamente referida à atuação no magistério não pode ser menosprezado.

Nessa linha de raciocínio, recorre-se a Horkheimer e Adorno (1985). Os autores alertam para o fato de o sistema ser organizado para que o pensamento não tenha unidade, e, portanto, "para não falar da unidade do sistema, para o qual tudo está dirigido. Produzir essa unidade é a tarefa consciente da ciência" (p.82). Em face de tais reflexões, e tendo como foco de análise a estrutura organizacional da SEE/SP, pode-se inferir que a relação entre indivíduos, formação e conhecimento acaba definindo as opiniões dos professores, o que permite pensar nos cursos oferecidos pelos órgãos gestores, seja em HTPC ou em qualquer outra modalidade, como os de extensão e os debates realizados (a partir de palestras e conferências) que enfatizam que os professores aprendem a dar aulas na prática, como maneiras de

conteúdos que estavam trabalhando, ou seja, se estavam "aplicando" a proposta oficial. Outro exemplo é a pesquisa de Mirisola (2012) que, ao pesquisar sobre o curso oferecido pela SEE/SP para a inserção dos novos professores na rede estadual paulista, concluiu que tal curso ao mesmo tempo em que promove a inserção profissional e o acolhimento do ingressante, também tende à padronização da atuação docente. Olh@res, Guarulhos, v. 2, n. 2, p. 86-110. Dezembro, 2014. 
se produzir consenso em torno da política imposta por aqueles que ocupam cargos de poder e prestígio na cena educacional. De qualquer modo, a formação nos locais de trabalho ou para o trabalho são direcionadas para a integração dos indivíduos e, portanto, contribuem para ratificar os padrões estabelecidos e perpetuar a alienação, o que impede a reflexão e a formação, pois "do trabalho alienado, assim, resultam o conformismo e a impotência do trabalhador" (CROCHÍK, 2003, p.71)

Acerca da relação entre trabalho, formação e alienação são destacadas as ponderações de Horkheimer e Adorno (1985), que sinalizam para o processo a partir do qual acontece a socialização (muitas vezes realizada por meio de cursos e de treinamento) que ocorre nos locais de trabalho. Para esses autores, a formação para a emancipação não pode sobrevir de qualquer maneira e, ao relacionarem formação, socialização e trabalho, alertam para o fato de que não se trata de formação em seu sentido genuíno, mas apenas um modo de consumar a alienação. Essa argumentação ganha consistência quando são considerados outros dados coletados. O cruzamento da opinião sobre a organização do ensino em vigor com a realização de cursos de formação continuada está expresso na próxima tabela.

Tabela 3: Relação entre formação continuada e opinião sobre a organização do ensino em ciclos com progressão continuada

\begin{tabular}{|c|c|c|c|c|c|}
\hline Realizou algum curso de formação continuada & \multicolumn{2}{|c|}{ Sim } & \multicolumn{2}{|c|}{ Não } & \multirow{2}{*}{ Total } \\
\hline $\begin{array}{l}\text { A organização do ensino em } \\
\text { ciclos com progressão continuada é continuada }\end{array}$ & Freq. & Prop. & Freq. & Prop. & \\
\hline Boa & 8 & 0.22 & 2 & 0.05 & 10 \\
\hline Ruim & 17 & 0.46 & 10 & 0.27 & 27 \\
\hline TOTAL & 25 & 0.68 & 12 & $\mathbf{0 . 3 2}$ & 37 \\
\hline
\end{tabular}

Olh@res, Guarulhos, v. 2, n. 2, p. 86-110. Dezembro, 2014. 
A tabela 3 ratifica a discussão assinalada anteriormente. Se a formação oferecida no âmbito do sistema educacional não pode ser considerada como aquela que proporciona emancipação (sequer no plano do pensamento), os dados da tabela sinalizam o quanto a frequência a esses tipos de cursos influenciam as percepções das professoras sobre o sistema de ensino: das 10 professoras que mencionaram que a organização do ensino em ciclos com progressão continuada é "boa", oito realizaram algum curso de formação continuada e apenas duas não o fizeram. Sem a pretensão de produzir uma conclusão definitiva sobre esse aspecto, mas ao mesmo tempo não negando a tendência verificada, tais dados permitem identificar que a formação continuada, tendencialmente, contribuiu para a inculcação da política oficial na forma de pensar dos professores.

A propósito das influências sofridas pelos profissionais do ensino, expõem-se os dados sobre as fontes que mais contribuíram para o entendimento das professoras acerca dos conceitos de ciclos e progressão continuada. Elas tiveram como opção assinalar a afirmação que mais expressava suas opiniões, tendo ainda a possibilidade de, quando essas opiniões estivessem apresentadas em mais de uma, assinalarem 1 para sua primeira opção, 2 para a segunda e assim pordiante. Temos: a $1^{\text {a }}$ opção com 36 respostas, a $2^{\mathrm{a}}$ com 33 e a $3^{\mathrm{a}}$ com 28, totalizando 97 respostas, conforme disposto na tabela 4, que sintetiza o número total de vezes que os enunciados da questão são escolhidos. Do apresentado a seguir, destaca-se o fato de que os quatro primeiros enunciados, que aparecem com maior número de respostas e estão em negrito, correspondem à formação pelo e no trabalho, isto é, as professoras disseram aprender sobre ciclos e progressão continuada no âmbito da própria atividade docente. Os quatro últimos, com menor 
número de respostas, se referem à formação não restrita apenas a sua relação direta com o trabalho.

Tabela 4 - Síntese das fontes, indicadas pelas professoras, que permitiram o entendimento acerca dos conceitos de ciclos e progressão continuada

\begin{tabular}{|c|c|c|}
\hline $\begin{array}{l}\text { Fontes de influência na forma de pensar e entender } \\
\text { os conceitos de ciclos e de progressão continuada }\end{array}$ & Número de respostas & Proporção \\
\hline Nas reuniões de HTPCs. & 26 & 0.27 \\
\hline $\begin{array}{l}\text { No próprio decorrer de minha experiência como } \\
\text { professora da rede pública estadual paulista, pois em } \\
\text { minha formação não tive contato com os ciclos e a } \\
\text { progressão continuada. }\end{array}$ & 22 & 0.23 \\
\hline $\begin{array}{l}\text { Embora em minha formação eu tenha estudado a } \\
\text { organização do ensino em ciclos e a progressão } \\
\text { continuada, fui entendê-los melhor na rede estadual, } \\
\text { pois a forma implantada pela Secretaria da Educação } \\
\text { influenciou meu modo de pensar e atuar. }\end{array}$ & 18 & 0.19 \\
\hline $\begin{array}{l}\text { Leitura de textos oficiais dispostos no site da } \\
\text { Secretaria da Educação. }\end{array}$ & 12 & 0.12 \\
\hline $\begin{array}{l}\text { Em minha formação inicial (magistério, normal } \\
\text { superior, pedagogia). }\end{array}$ & 8 & 0.08 \\
\hline $\begin{array}{l}\text { Leitura de revistas de educação, como Nova Escola, } \\
\text { por exemplo. }\end{array}$ & 5 & 0.05 \\
\hline Leitura de artigos científicos e livros. & 4 & 0.04 \\
\hline Em cursos realizados após minha graduação. & 2 & 0.02 \\
\hline TOTAL DE RESPOSTAS & 91 & 1.00 \\
\hline
\end{tabular}

Os dados aqui apresentados contribuem com a análise do trabalho como espaço formativo para as professoras. De um total de 97 respostas, as contidas nas opções destacadas em negrito somam 78. Tais enunciados foram elaborados com a intenção de apreender a força da SEE-SP como fator de maior influência, enquanto os enunciados que

Olh@res, Guarulhos, v. 2, n. 2, p. 86-110. Dezembro, 2014. 
remetiam às influências externas na forma de pensar e entender (os outros que não estão em negrito) foram apontados somente em 19 respostas. Isso fortalece o fato de que a formação das professoras é realizada pelo próprio sistema no qual trabalham.

Contrário a esse tipo de formação, Adorno (1972, p. 166), quando relaciona a formação dos indivíduos com o sistema social, enfatiza que "para satisfacer em cualquier caso los requisitos que la sociedade dirige a los hombres, la formación se reduce a las marcas distintivas de la anmanencia e integración sociales, y se conviertes in reservas em algo intercambiable y aprovechable"; a formação acaba determinada pela necessidade de conferir valor de troca às habilidades do indivíduo e, também, de proporcionar capacidade de desempenho eficiente.

Ainda sobre as influências sofridas pelas professoras, também se inqueriu sobre as fontes de conhecimento acerca da educação na rede pública estadual paulista. A questão foi redigida da seguinte maneira: marcando de 1 a 12 em ordem crescente - sendo 1 para a de maior influência e 12 para a de menor influência -, expresse como sua opinião sobre questões do dia a dia da educação é formada. Para análise dos dados criou-se uma forma de pontuação: aquele enumerado pelas professoras com 1 , portanto primeira opção, recebeu 12 pontos, o número 2, recebeu 11 pontos e assim por diante. Identificou-se também o número de vezes que o enunciado apareceu entre as três primeiras escolhas. Tal questão foi respondida por 26 professoras e os dados estão dispostos na tabela a seguir.

Tabela 5: Fontes de influência sobre as professoras no que se refere à educação

\begin{tabular}{l|c|l}
\hline Fonte de influência & Pontuação & $\begin{array}{l}\text { Número de vezes que aparece entre } \\
\text { as três primeiras escolhas }\end{array}$ \\
\hline Leitura de livros & 234 & 15
\end{tabular}

Olh@res, Guarulhos, v. 2, n. 2, p. 86-110. Dezembro, 2014. 
Nos HTPCs

Acesso ao site oficial da Secretaria do Estado da Educação

Revistas de Educação como Nova Escola, dentre outras

Cursos que realizou ou está realizando

Conversas com amigos de trabalho

Leitura de artigos científicos

Revistas semanais como Veja, Época, dentre outras

Imprensa - Jornal

Imprensa - televisão

Sindicatos

Partidos políticos

\begin{tabular}{l|l}
232 & 14 \\
202 & 3 \\
201 & 6 \\
193 & 14 \\
182 & 4 \\
159 & 4 \\
156 & 3 \\
151 & 3 \\
135 & 5 \\
59 & - \\
58 & 1
\end{tabular}

Os dados sobre os veículos que mais influenciam as opiniões das professoras sobre educação tornam-se relevantes à medida que permitem conhecer um pouco melhor as experiências formativas dos profissionais do ensino. Um dos destaques diz respeito à baixa valorização dos sindicatos e partidos políticos como fonte de influência das opiniões, aparecendo como os dois últimos e com as menores pontuações - com 58 e 59 pontos respectivamente - e somente uma vez entre as três primeiras escolhas, o que, de certa forma, aponta a abstenção do debate que tem lugar nessas instituições. Esse fato é comprovado quando se compara sua pontuação com a da alcançada pela imprensa (televisão: 135 pontos; jornal: 151 pontos; revistas semanais: 156 pontos). Esse dado permite identificar que os meios de comunicação de massa são maiores referências para as professoras do que as instituições relacionadas diretamente ao âmbito político. A influência dos meios de comunicação de massa em detrimento de outras formas de socialização (como a oferecida por sindicatos, partidos

Olh@res, Guarulhos, v. 2, n. 2, p. 86-110. Dezembro, 2014. 
políticos e outras associações) foi vista com desconfiança por Adorno (1987). O autor questiona as possibilidades formativas oferecidas por esses veículos. Destaca-se também Marcuse (1969, p.102). Ao apontar o fato de os meios de comunicação de massa terem se tornado os mediadores entre o conhecimento e o indivíduo, o autor enfatiza que "com o declínio da consciência, com o controle da informação, com a absorção do indivíduo na comunicação em massa, o conhecimento é administrado e condicionado".

Maar (2006, p.25-26) assinala que "os bens culturais que alimentam as massas tornam dominante o processo da adaptação, enquadrando-se numa sociedade adaptada, e rompem a memória do que seria autônomo". Não se trata aqui de defender os sindicatos e os partidos políticos como formadores por excelência dos posicionamentos das professoras, mas é fundamental refletir sobre o recuo da influência sindical e partidária nas experiências formativas.

De qualquer maneira, a leitura de livros, com 234 pontos e 15 aparições entre as primeiras escolhas, foi apontada como a maior influência para as professoras, seguida dos HTPCs que, com 232 pontos e 14 aparições entre as primeiras escolhas, ficando a frente dos demais enunciados: “cursos que realizou ou está realizando”, com 193 pontos e 14 aparições entre as primeiras escolhas; "leitura de artigos científicos" com 159 pontos e quatro aparições entre as primeiras escolhas. Destacam-se do apresentado dois aspectos. Um diz respeito à baixa adesão das professoras ao enunciado que versava sobre os artigos científicos - aparece na sétima posição. Não se quer valorizar os artigos científicos como fontes privilegiadas de conhecimentos, e a simples leitura deles não garante que aconteça experiência intelectual nos ternos definidos por Adorno (1972), mas refletir sobre o segundo aspecto a saber: a posição dos HTPCs - apenas dois pontos atrás da leitura de 
livros. Se somarmos essas escolhas com algumas outras (acesso ao site oficial da Secretaria do Estado da Educação e Conversas com amigos de trabalho), podemos traçar um panorama sobre o lugar onde ocorre a formação de opinião das professoras sobre as questões educacionais. Trata-se de posicionamentos nascidos no próprio ambiente de trabalho. Conforme demonstrado, os enunciados que apontaram o próprio trabalho como fator de influência na formação da opinião aparece com maior pontuação, por exemplo, do que os artigos científicos.

\section{Considerações Finais}

O presente texto visou apreender como as experiências de formação continuada de um grupo de professoras atuantes no ciclo I da rede pública estadual interferem nas percepções que possuem acerca da organização do ensino em ciclos com progressão continuada implantada a mais de 15 anos na rede pública estadual paulista.

Os dados apontaram que a formação continuada das professoras que compuseram a amostra é realizada em sua maior parte pela própria SEE/SP, ou seja, pelo próprio lócus de trabalho que estão inseridas, e, por conseguinte, tal formação vem em consonância com os discursos das políticas oficiais. Não se quer afirmar que a tendência de submissão das professoras ao que é oferecido pelo próprio sistema seja o responsável pelas mazelas da educação e da escola. Apenas sublinhar os fatores que influenciam as opiniões das professoras, com destaque para os mecanismos utilizados pela SEE/SP para exercer o controle sobre o que acontece nas escolas. De qualquer modo, a formação nos locais de trabalho ou estritamente vinculadas à atividade pedagógica acaba voltada predominantemente para o aspecto prático da profissão 
docente, depurando-a de sua dimensão política. Essa situação é reforçadora da pseudoformação. Conforme Crochík (2004, p.69), “a cultura como um fim em si mesmo não é menos pseudoformação do que a formação para o trabalho". Assim, não se trata de redirecionar a formação continuada oferecida aos professores no sentido da valorização dos conhecimentos advindos das teorias sociais $\mathrm{e}$ educacionais - tal virada não produziria soluções para os problemas da educação -, mas de indicar a falta de escolhas imposta aos professores e seu impacto no processo que redunda no cerceamento das consciências. Portanto, a formação no local de trabalho (na escola ou nas diretorias de ensino), tendo em vista as condições em que ocorre na rede de ensino estadual, contribuiu para reforçar à pseudoformação.

De acordo com Adorno (1972), nas circunstâncias em que a formação vem acompanhada de estruturas heteronômicas em que o individuo deve submeter-se para formar-se, a formação em seu sentido estrito já não ocorre mais. Diante do exposto, parece ser patente que a tendência geral é a da pseudoformação. E esta mantém ligações com as condições objetivas as quais os indivíduos estão submetidos ou, como enfatiza Adorno (1972, p.169), “lo producido objetivamente es más bien la indole subjetiva que hace impossible la comprensión objetivamente possible". As reflexões de Adorno ao serem cotejadas com os dados aqui encontrados desencadeiam uma discussão relevante, a saber: a formação no âmbito do trabalho é pseudoformação por ser uma formação voltada para atender às demandas do sistema. 
Formação continuada e políticas educacionais: relação de um grupo de pedagogas com a progressão continuada

\section{Referências}

ADORNO, Theodor. Teoria de La seudocultura. In: Sociologia. Madrid, Taurus Ediciones S.A., p. 233-267, 1972.

A Indústria Cultural. In: COHN, Gabriel.(org). Comunicação e Indústria Cultural. São Paulo: T. A. Queiroz, 1987

A filosofia e os professores. In: Educação e emancipação. Rio de Janeiro: Paz e Terra, 2006.

CROCHÍK. José Leon. La pseudoformacion y la consciência ilusionada. In: Revista Educação 26 y Pedagogia 27. v. VII. Colombia. Universidade de Antioqua/Faculdade de Educación, 2000.

Notas sobre trabalho e sacrifício. Trabalho, Educação e Saúde,1(1):61-73, 2003

O desencanto sedutor: a ideologia da racionalidade tecnológica. Inter-ação (Goiânia), Goiás, v. 28, n.1, p. 15-35, 2004.

DIAS-DA-SILVA, Maria Helena Frem; LOURENCETTI, Gisela do Carmo. A voz dos professores e algumas reformas educacionais nas séries finais do ensino fundamental: desencontros ou impasses? In: SAMPAIO, Maria das Mercês Ferreira (org). O cotidiano escolar frente às políticas educacionais - $1^{\mathrm{a}}$ edição. Araraquara: JM Editora, 2002.

DIAS, Vagno Emygdio Machado. A organização escolar em ciclos: um estudo sobre a Progressão Continuada do Estado de São Paulo. Dissertação de Mestrado. Educação UFSCAR - São Carlos, 2004.

FERNANDES, Anoel. A proposta pedagógica para a Educação Física escolar nas séries iniciais da rede pública estadual paulista: as manifestações dos professores. Dissertação de Mestrado em Educação: história, política, sociedade. Pontifícia Universidade Católica de São Paulo, 2009.

FREITAS, Luiz Carlos de. Ciclos de progressão continuada: vermelho para as políticas públicas. Revista Eccos, São Paulo, v.4, n.1, p. 79-93, junho, 2002.

2003

Ciclos, seriação e avaliação: confronto de ideias lógicas. São Paulo: Moderna,

Olh@res, Guarulhos, v. 2, n. 2, p. 86-110. Dezembro, 2014. 
. A avaliação e as reformas dos anos de 1990: novas formas de exclusão, velhas formas de subordinação. Educação e Sociedade, Campinas, v. 25, n.86, p. 133-170, 2004.

HORKHEIMER, Max e ADORNO, Theodor. Temas básicos de Sociologia. São Paulo: Cultrix, 1973.

Dialética do Esclarecimento. Rio de Janeiro: Jorge Zahar, 1985.

MAAR, Wolfgang Léo. Semiformação e Educação. Educação e Sociedade, Campinas, v. 24, n.83, p. 459-475, 2003.

À guisa de introdução: Adorno e a experiência formativa. In: ADORNO, Theodor W. Educação e emancipação. Rio de Janeiro: Paz e Terra, 2006.

MARCUSE, Herbert. $A$ ideologia da sociedade industrial. Rio de Janeiro: Zahar Editores, 1967.

. Eros e Civilização: uma interpretação filosófica do pensamento de Freud. Rio de Janeiro: Zahar Editores, 1969.

MIRISOLA, Cristina Dias. Inserção profissional docente no estado de São Paulo: a escola de formação e o curso para professores ingressantes da SEE/SP. (Mestrado em Educação: história, politica, sociedade). Pontifícia Universidade Católica de São Paulo, 2012.

RESENDE, Maria do Rosário. A educação com base em uma formação para a emancipação: uma reflexão. Inter-Açao: Revista Faculdade de Educação da UFG, Goiânia, p.37-49, 2003.

SÃO PAULO (ESTADO). Deliberação CEE 9/97. Institui, no Sistema de Ensino do Estado de São Paulo, o regime de Progressão Continuada no ensino fundamental. DOE de 05 de maio de 1997

CEE. Indicação CEE no. 22/97, de 17 de dezembro de 1997. Avaliação e Progressão Continuada. Diário Oficial do Estado de São Paulo, seção I, p. 18, 20 de dezembro de 1997.

SELLTIZ, Claire et. al. Métodos de pesquisa nas relações sociais. Tradução de Dante Moreira Leite. 4ªReimpressão. São Paulo: EPU, 1974.

Olh@res, Guarulhos, v. 2, n. 2, p. 86-110. Dezembro, 2014. 